\title{
Urban form in the tourist cities of the coast of the Canary Islands. The morphologies of the leisure activities
}

\author{
Rafael Temes Cordovez ${ }^{\mathbf{1}}$, Moisés Simancas $\mathrm{Cruz}^{\mathbf{2}}$, Alicia García Amay \\ María Pilar Peñarrubia Zaragoza ${ }^{3}$ \\ 'Departamento de Urbanismo. Universitat Politècnica de Valencia, Spain \\ ${ }^{2}$ Departamento de Geografía e Historia. Universidad de La Laguna, Spain \\ ${ }^{3}$ Departamento de Geografía. Universitat de València, Spain \\ E-mail: rtemesc@urb.upv.es,msimancas@ull.edu.es, alicia@garciaamaya.com, M.Pilar. \\ Penarrubia@uv.es
}

\begin{abstract}
The tourist city has been a space with few reflections from the urbanistic discipline. Not in vain, the developed planning, at best, has been uncritically exported from the residential city. However, these cities generate almost $12 \%$ of Spanish GDP. The vast majority of Spanish coasts, especially on the Mediterranean coast and in the archipelagos, are occupied by large extensions of leisure towns, many of them born of the first boom of Spanish tourism in the 60s. The predominant mass tourism model on our coast also generates a mass city whose morphology does not follow the common and more consolidated patterns of the residential city. In this work, we propose the analysis of two micro destinations in the Canary Islands (Puerto de la Cruz Tourist and Adeje Tourist / Las Américas-Los Cristianos), characterized by its great contrasts, and will focus our identification on the morphological evolution of a minimal piece of tourism: the hotel.
\end{abstract}

Keywords: Tourism, hotel, standards, Canary Islands

\section{Introduction}

It is paradoxical to admit that, being Spain for several decades, one of the world leaders in the tourist industry, with all that it entails: services, transport, locations, resources ..., its architecture and urbanism, that has given the urban form to these leisure spaces, have not been a special object of study or specialization in our schools (Pié, 2015). Far from it, it is often recognized, that leadership in this type of activities is not accompanied by studies or research lines that allow learning from the mistakes and propose new solutions to this complex activity. With the exception of some cases, the shadow of the "shameful architecture" (Pié, 2002) and by extension of "foreing urbanism" have predominated in the disciplinary landscape leaving a bulky linear void on the seafront.

Fortunately, in recent years there seems to be a renewed reflection on these areas in which, either because of the exaggerated occupation of the coastal strip, by the deterioration of the landscape or directly by the interest in the renovation of "tourist cities", there is a greater interest from the urbanistic discipline to understand and to know how they have been constructed the emporiums of the leisure.

This lecture is part of a wider research framed within the $\mathrm{R}+\mathrm{D}+\mathrm{i}$ Project entitled "Geographic Information Technologies applied to the analysis and design of innovative proposals for the renovation of tourist accommodation", funded by the CajaCanarias Foundation. It is also part of the project entitled "Crisis and Restructuring of tourist areas on the Spanish Coast" (CSO2015-64468-P) of the Ministry of Economy and Competitiveness (MINECO). Within these projects, a line of research developed deals with the analysis and description of the urban form of tourism 
especially in the Canary Islands. One of the results of the research tries to obtain the "Atlas of the Canary Islands Tourist Renewal", a graphic tool that allows us to know spatially the distribution of forms of tourism in the coast of the islands and at the same time their potential for renewal. Having an inventory and assessment of the physical construction of tourism has been a goal several times claimed (Mesalles, F., \& Tous, J. 2003; Pié, 2015; Temes \& Tuset, 2015). Specifically, in the case of tourism, the statistical and cartographic study has the same difficulties as any territorial project, but it is aggravated by the inherent disadvantages of this type of activity -imprecision in the definition of the tourist, difficulty and reliability of records and surveys or the impossibility of comparing information(Pié, 2015).

To do this, it is essential to know the urban form of the destinations, to understand their typologies and morphologies and how they respond in a singular way to the tourist activity. Hence the work with "minimal pieces of tourism" as "management units and construction of the tourist territory and the structures that allow to adjuste them in a proper spatial planning to this form of land occupation, analyzing social, technical, cultural and economic factors that have conditioned it." (Barba, 1996). In this paper we will offer some partial results of this analysis by establishing a comparison between two micro destinations of special relevance in the Canary Islands: The micro destination of southern part of Tenerife formed by "Adeje Turístico" 12 and "Las Américas-Los Cristianos" and the micro destination of the north of Tenerife "Puerto de la Cruz Turístico".

\section{Methodology}

Considerations about the urban form and the particular perspective offered by the morphological-based studies, have had in Spain an interesting tradition with influences mainly from the Italian, Anglo-Saxon and French culture (Whitehand, 2001; Pinho \& Oliveira, 2009). This initial influence gave way in the 70s to its own methodology of analysis "morpho-typological" mainly driven from the
Department of Urbanism of the Universitat Politècnica de Catalunya (UPC) and then extended to many other research centers. In "Forms of urban growth" (Solá Morales, 1993), the name used by this methodology, urban fabrics are classified according to the construction process, the relations that are established between the design of the ground, the urbanization of the land and the construction of the buildings. Depending on the order and the characteristics of each one of them, the result is different. This methodology is very useful not only to recognize the characteristics of the urban conglomerate and delimit its parts, but also to project the urban space, because you can use the same parameters for the analysis and the architectural project of the place. However, they are not useful for the analysis of the areas with tourist developments (Pié, 2015). In this case, the tourist space can be qualified according to the taxonomy of the "minimum pieces of tourism" already mentioned in the introduction of this work. If in "forms of urban growth" what matters is the morphological rule with which an urban fabric develops, in the "minimal pieces of tourism", it is their level of autonomy, a basic question in "tourist artifacts", especially in its first implantations.

Although the original method of analysis defines at least four types of "minimal pieces": accommodation, equipment, infrastructure or services and the large equipment, in this analysis we only go to focus on accommodation parts and, specifically, on the hotels, leaving the rest for a further development of the work. In addition, as an analysis tool that has proven to be very useful in the morphologist's line, we use a Geographic Information System (GIS) that allows us to understand and to explain the construction of the tourist areas through its various growth strategies.

\section{The Areas of study: Puerto de la Cruz Turístico and Adeje Turístico/Las Americas- Los Cristianos}

In the analysis of the morphology of the tourism, we have wanted it to focus in this lecture, in the case of the island of Tenerife. The reason has been to contrast two very different microdestinos and very distant from each 
other. The case of Puerto de la Cruz, a tourist settlement in the north of the island, pioneer in the Canary Islands and characterized for being a model that has coexisted with a traditional urban settlement, and the case of Adeje Turístico /Las Americas-Los Cristianos, settlement in the south of Tenerife, representative of the mass tourism model in which it is possible to distinguish virtually all stages of the tourist boom and the growth of the settlements in the Canary Islands (Simancas, 2015).

The micro destination "Puerto de la Cruz Turístico" has as a great attribute to unite in one place a landscape of great urban density next to a natural landscape of an amazing energy. In a space of less than ten square kilometers the visitor finds many urban experiences. In the same center of the city we find the area of Martianez, with buildings of more than 15 floors, which give the city a vocation of great metropolis, and allow the visitant to enjoy the proximity of services guaranteed by the concentration of activities. At the same time, from a large number of streets, you can glimpse, looking toward the interior of the island, the image of the peak of Teide. Its imposing image is framed by the Valley of La Orotava. A few minutes walk from anywhere, you get to see the sea, the Atlantic Ocean which bathes the volcanic coasts of the city with a wave beat always attractive for the walker, which has its maximum expression in the encounter between "Paseo de San Telmo", "Penitente" and "Punta del viento" the tip. But Puerto de la Cruz is also a charming place, full of small but lush tropical gardens, such as the famous Botanical Garden or the gardens of the Sitio Litre. Puerto de la Cruz is the dean of the tourism on the Canary Islands and currently has a $5.78 \%$ of the establishments and apartments open with 83 facilities and a $5.33 \%$ of the number of places available with a total of 21,428 places. (Table 1)

The nucleus formed by Adeje Turístico and Las Américas-Los Cristianos, is the most important tourist city of the southwest of the Island of Tenerife and one of the main tourist destinations of the Canary archipelago. The territorial scope presents, by its size and development, a diverse and complex internal structure, configuring itself as the sum of areas with differentiated urban characteristics from a morphological and functional point of view, better or worse articulated among themselves. Unlike Puerto del Cruz, it is not part of a consolidated urban nucleus, but rather a "virgin" territory in which partial plannings were developed, resulting in one of the densest and largest tourist settlement in the Archipelago. In this case we speak of a concentration of more than 200 tourist facilities that represent $22 \%$ of the tourist accommodation in the Canary Islands.

\section{The definition of standards for the construction of the tourist ground}

Article 5.2(c) of the Law 7/1995, of 6 April, of the Canary Islands Tourism Planning, establishes the competence of the Public Administration of the Autonomous Community of the Canary Islands, the planning and management of tourism at the regional level, including the management of the offer, as well as the planning and programming on tourism infrastructure of regional interest. In the case of the Canary Islands, there are legislative references in the Decrees 149/1986, of 9 October, the management of hotel establishments, and 23/1989, of 15 February, on the management of tourist apartments, related to the establishment of tourist standards. However, it is not until the promulgation of the Law 7/1995, of 6 April, of the Canary Islands Tourism Planning, which begins to articulate a model of tourism development, which is concretized with the approval of the Management Guidelines of the Tourism (Law 19/2003, of 14 April), and, specially, of the Decree 10/2001, of 22 January, when the regulation of tourist standards occurs: whereas in Article 35 of the first rule stablishes minimum standards relating to the tourist development, the second sets a series of minimal physical parameters of the different structural elements of the tourist accommodation (size of the rooms, percentage of green areas and sports activities, etc.). In this way, Decree 10/2001 solves a question widely demanded by all sectors involved in the tourist activity, which considered it necessary to establish general weighting criteria to determine the minimum density standard, its application to subdivisions 
Table 1. List of places and establishments in micro-destinations

\begin{tabular}{|c|c|c|c|c|}
\hline & $\begin{array}{c}\text { Open establish- } \\
\text { ments }\end{array}$ & $\begin{array}{c}\% \text { in rela- } \\
\text { tion to Ca- } \\
\text { nary }\end{array}$ & $\begin{array}{l}\text { Places avai- } \\
\quad \text { lable }\end{array}$ & $\begin{array}{c}\text { \% in rela- } \\
\text { tion to Ca- } \\
\text { nary }\end{array}$ \\
\hline LANZAROTE & 262 & $18,25 \%$ & 72.026 & $17,91 \%$ \\
\hline FUERTEVENTURA & 162 & $11,28 \%$ & 62.432 & $15,52 \%$ \\
\hline GRAN CANARIA & 589 & $41,02 \%$ & 130.834 & $32,53 \%$ \\
\hline TENERIFE & 423 & $29,46 \%$ & 136.900 & $34,04 \%$ \\
\hline ADEJE & 92 & $6,41 \%$ & 43.548 & $10,83 \%$ \\
\hline - Callao Salvaje & 8 & & 2.536 & \\
\hline - Playa Paraiso & 6 & & 3.854 & \\
\hline - Playa de El Duque & 22 & & 11.778 & \\
\hline - Costa Adeje & 40 & & 20.209 & \\
\hline - Torviscas - Fañabé Alto & 16 & & 5.171 & \\
\hline LAS AMERICAS - LOS CRISTIANOS & 110 & $7,66 \%$ & 44.876 & $11,16 \%$ \\
\hline - Las Américas - Adeje & 12 & & 5.338 & \\
\hline - Las Américas - Arona & 56 & & 27.652 & \\
\hline - $\quad$ Los Cristianos & 42 & & 11.886 & \\
\hline ABONA & 41 & & 7.673 & \\
\hline ISORA & 25 & & 8.387 & \\
\hline PUERTO DE LA CRUZ TURÍSTICO & 83 & $5,78 \%$ & 21.428 & $5,33 \%$ \\
\hline - Playa jardín - Maritim & 15 & & 4.635 & \\
\hline - Conjunto Histórico & 30 & & 3.364 & \\
\hline - $\quad$ Taoro - La Paz & 29 & & 9.648 & \\
\hline - Martiánez & 9 & & 3.781 & \\
\hline \multirow[t]{2}{*}{ OTHER MUNICIPALITIES OF TENERIFE } & 72 & & 10.988 & \\
\hline & 1.436 & & 402.192 & \\
\hline
\end{tabular}

of plots, as well as the establishment of the minimum parameters of infrastructure and necessary services applicable to the totality of the tourist ground. To be more specific, art. 2 of that Decree establishes:

1. The standard density of tourist use, determines the minimum net plot area required for the construction of each tourist accommodation.

2. The standarscomplementary equipment determine the minimumreserves of equipment with which the tourist establishments of accommodation have to count.

3. The standards of infrastructure and services determine the minimum infrastructure that the new tourist developments have to offer.
In this study, we will focus on offering some results on one of the most important minimum parts of tourism: the hotels. We will discuss how over the past 60 years have evolved the morphologies and how the implementation of the standards has a decisive influence on the change of model from one period to another.

Minimum pieces of accommodation of tourism in the Canary Islands.

Using as representative areas of these morphology, the north and the south of Tenerife, which account almost $30 \%$ of the canarian tourism we can distinguish between hotel and extra-hotel supply. Inside of this classification, we can find according to the Bylaw of procedure of the tourist accommodation activity (Table 2) different minimum pieces of tourism in terms 
of their characteristics, the form of grouping, service and representativeness. From this relation, the predominant tourist settlement models in the Canary Islands are the hotels and the apartments. In the case of Tenerife hotel offering is greater than that offered in modality of apartments. Over the past 40 years, these models have been changing and we can find differentiated patterns in the north and south of the island. Let's move on to identify them.

Table 2. Category and typology of hotel and extra hotel settlements

\begin{tabular}{cc}
\hline Categorys & Typologies \\
\hline \multirow{3}{*}{ Hotels } & \\
\cline { 2 - 2 } & Hotel \\
& Urban Hotel \\
& Rilestone Hotel \\
& Rural Hotel \\
\hline \multirow{2}{*}{ Extra-hotels } & Apartment \\
& Villa \\
& Milestone House \\
& Rural House
\end{tabular}

Panoramico or vertical hotel and the terraced hotel (between party walls)(19501980)

This model of hotel, whose chronology can be placed between the $50 \mathrm{~s}$ and $70 \mathrm{~s}$, is the first model to respond in the Canary Islands to the mass tourism. From the point of view of their organization, in a general way, we talk about hotels formed usually by 2 clearly differentiated pieces. On the one hand, the ground floor or base where common services and collective facilities predominate. On the other hand, the body of rooms distributed in height, in one or two prisms representing the architecture of the modern movement. In the case of Puerto de la Cruz, within this general pattern we can describe two cases. On the one hand, the terraced hotels, inserted in the urban center of the original downtown area of El Puerto and on the other hand the vertical hotels. The hotels between party walls usually lack of green areas and promenade, and has its swimming pools on the upper floors. The average area of their plots, that is around $600 \mathrm{~m} 2$, does not allow many more facilities, using the city as a whole as compplementary equipment.

On the other hand, the first hotels in height, have a more generous plots, around 1.5 hectares and have free spaces, green areas, solarium and swimming pools. Regarding the proportion of this type of use, around $15 \%$ of the surface, increases up to $40 \%$ in the case of luxury hotels (Botánico, 1973 or Tigaiga, 1959). The layout of the buildings on the plot, usually adopt in the case of El Puerto an eccentric position and the buildings often have a prismatic geometry, very characteristic of the period. In addition, because of the topography in slope of El Puerto, the Panoramic hotel is not defined as a hotel in front of the sea, a very common condition at this time in the Mediterranean tourist, but it is a hotel with panoramic views of the sea and other resources that offer scenic views of the area. The orientation of the Puerto de la Cruz places the recreation areas and solarium at the rear of the plots with south orientation, placing the accommodation fronts normally parallel to the coastline. If this, it is linked to the important vertical component characteristic of El Puerto, with hotels up to 15 floors being for several decades the highest buildings on the island, we can see how these topographic conditions will be reflected in the morphological organization of the architecture.

In the case of the south of Tenerife, within this same modality, we can observe different behaviors. On the one hand, there will be no models between party walls, since the tourist areas are areas of new colonization. With regard to vertical or panoramic hotels, the practically flat topography of the area and the reduction of resources, focused especially on the sea and its beaches, give rise to a model of hotels with a wide perimeter development, either with parallel layout to the coastline as the Tenerife-Sol (1975) or Gran Tinerfe (1973) or with the balconies and terraces of the rooms oriented towards this direction, adapting to the conditions of their plots. A good example of these latter cases would be the Aparta-Hotel Club Bonanza (1971) or the Hotel-Apartment Ponderosa (1973). Unlike in Puerto de la Cruz, the existence of larger average plots (around 2 hectares) and the proportion of soils destined for services, swimming pools and green areas, 


\section{Puerto de la Cruz Turístico}

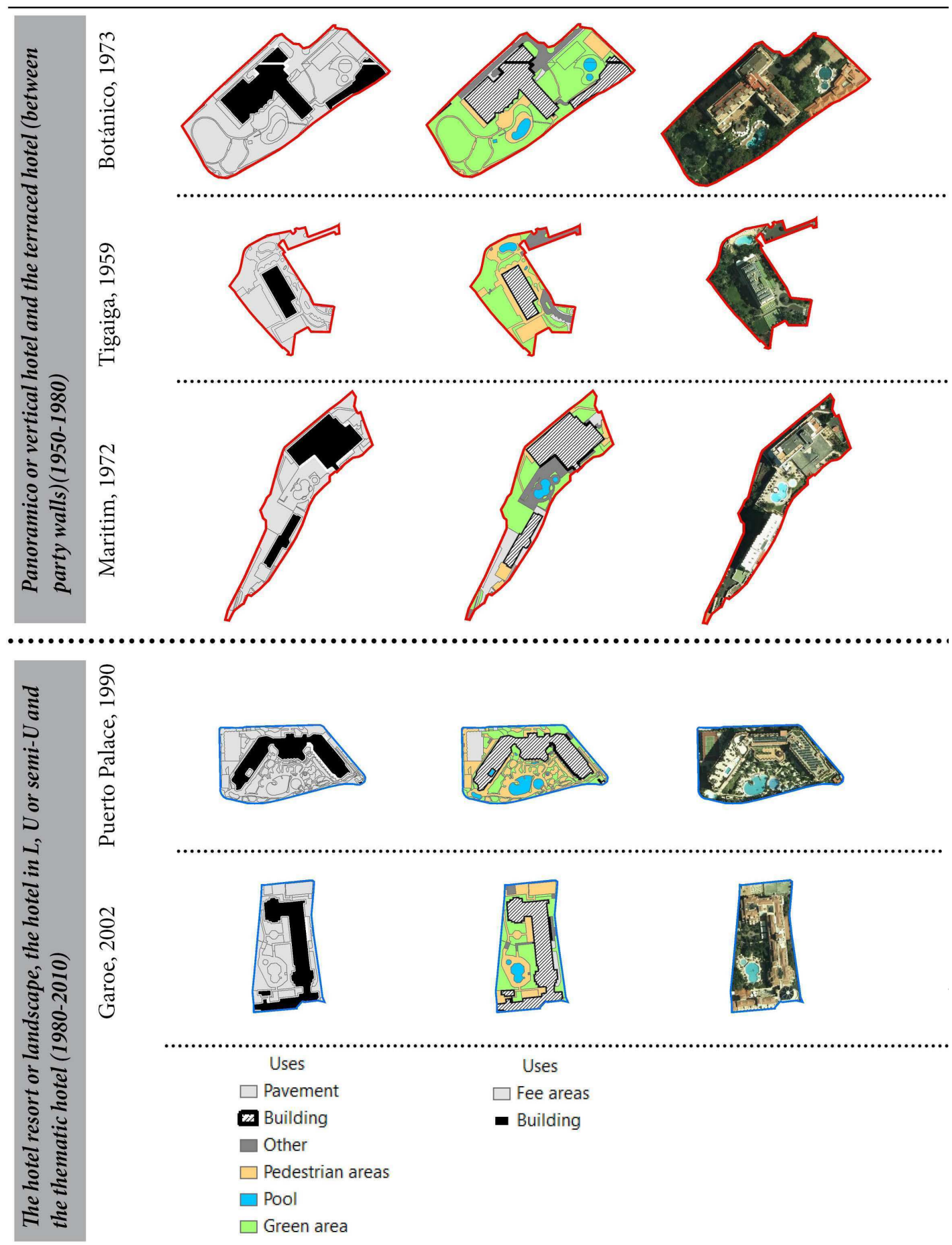

Figure 1.

Puerto de la Cruz turístico. Morphological evolution of the hotels of mass tourism 


\section{Adeje Turístico / Las Américas-Los Cristianos}

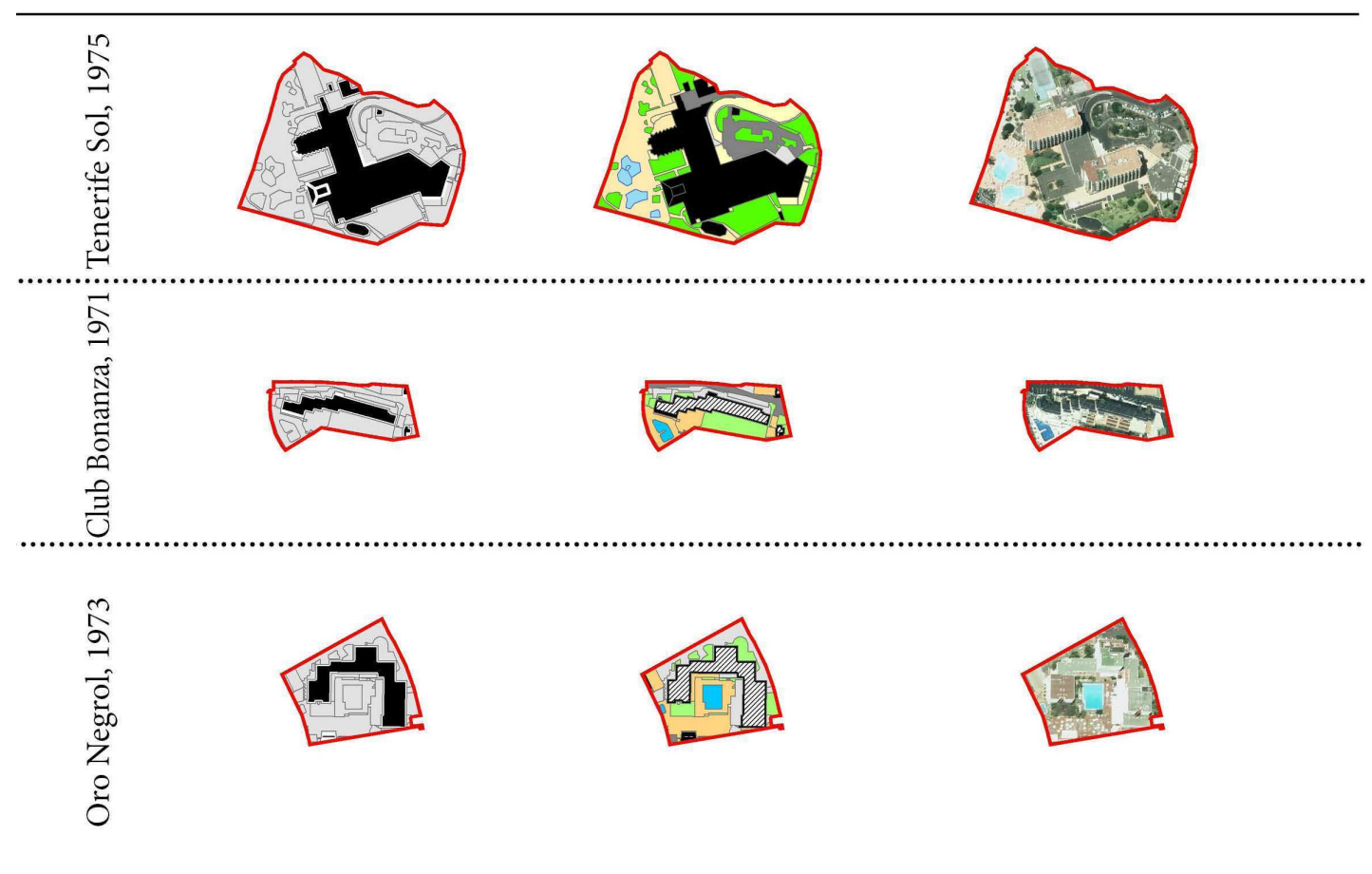

Bahía del Duque, 1993
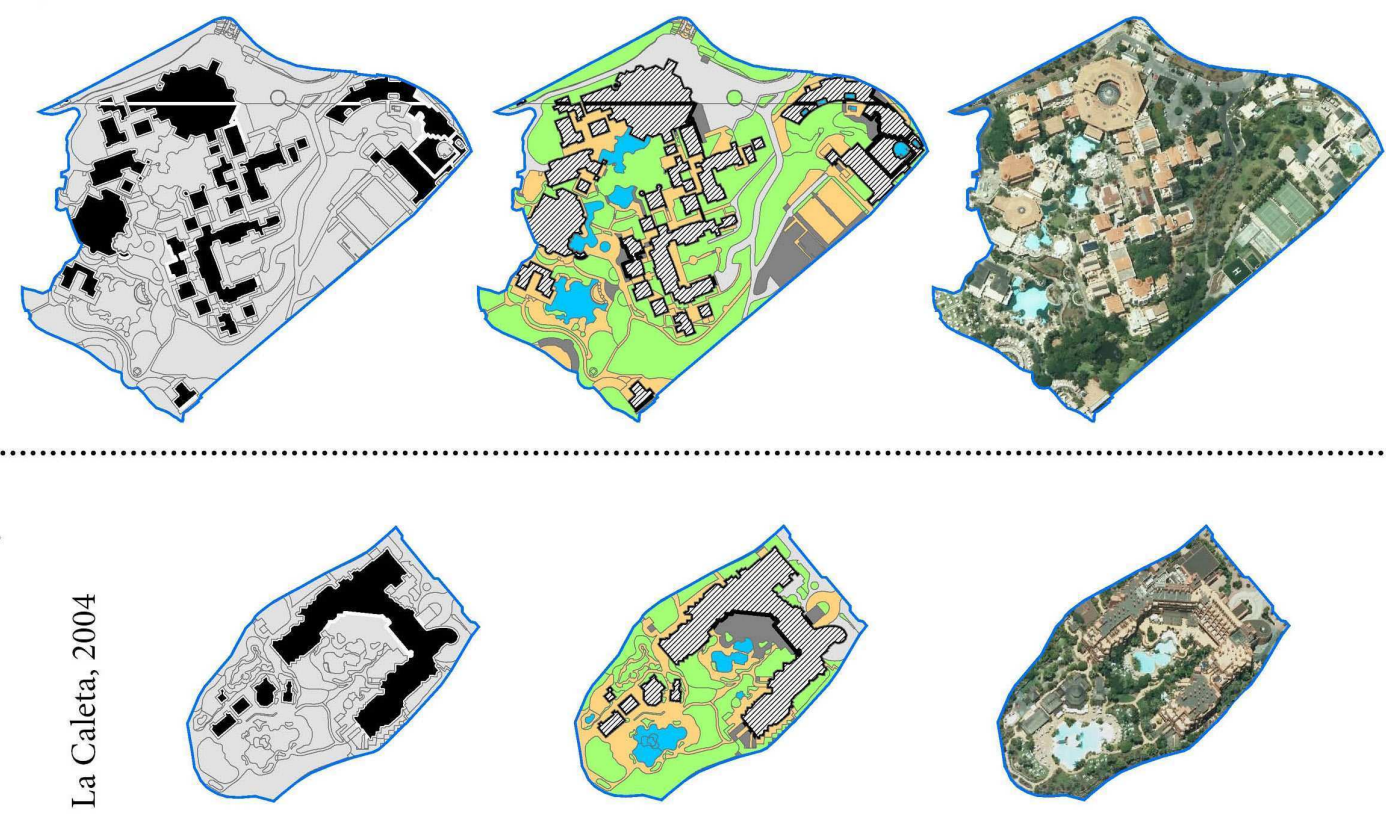

Figure 2.

Adeje turístico/Las Américas-Los Cristianos. Morphological evolution of the hotels of mass tourism 
which are also more generous too, have made these models coexist with U-shaped or semi-U arrangements, which envelop the new spaces of private equipment always with south or south-west orientations. This situation is given in both hotels, in first line of sea as the Hotel Las Palmeras (1973), that combine the position of their equipment to extend them with the landscape itself, or in other hotels located in positions away from the beaches, such as the case of the Hotel Oro Negro (1973), in which a landscape is recreated from the spaces of leisure and service of its own.

The hotel resort or landscape, the hotel in $\mathrm{L}$, $U$ or semi-U and the thematic hotel (19802010)

In this second group, the construction of hotels is going to be characterized by the size of its implementation, the volume built, by its relative position and, in the case of the south of Tenerife, since the $90 \mathrm{~s}$, by their thematization.

In the case of Puerto de la Cruz, the implementation in this second stage, will be conditioned by the existence of a quite consolidated nucleus with a coast line practically closed in the previous period. The hotels between party walls are practically testimonial during this period (Chimisay, 1980) or they are the first reforms of existing hotels previously (Astoria, 1993). The most frequent implantations will occur, as can be seen in the graph, inside the tourist destination, in plots slightly larger than those seen in the previous period, reaching a mean of 1.2 ha. In relation to the height of the volumes we must say that we are now with buildings with an average of 5 floors, well below the previous hotel provision and occupations in the floor not greater than $40 \%$ of the plots (Puerto Palace, 1990 or Garoé, 2002). This change will be much more appreciable in the South of Tenerife, where many more units will be built.

In the south of Tenerife we can distinguish 3 modalities of hotels within this range. In the first decade of analysis, between 1980-1990, we find the hotel in L-U and semi U. In the mid 90s, a new themed hotel model was introduced with the Gran Hotel Bahía del Duque (1993). From the late 90's until today, we find the horizontal hotel-resort itself, which is a direct consequence of the implementation of the standards of the Decree 2001.

Hotels with closed or semi-closed layout, already initiated in the previous period, now have their consolidation acquiring provisions in L, U or semi U. Unlike its predecessors, the plots are now somewhat higher (above the 1.3 hectares) and slightly lower heights, started to set up the horizontal or resort model to be introduced at the end of the period. Hotels representative of this morphology could be the Best Tenerife (1985), La Siesta (1986) or the Mediterraneum Palace (1987).

In the decade of the 90, the previous model coexists with a new product. The inauguration in 1993 of the Gran Hotel Baháa del Duque starts a new formula then followed by other hotels like Resort Mare Nostrum (1997) or the Costa Adeje Palace (1999) aimed to open up a new market based on specialization and in the provision of extensive facilities. Normally the architecture of these "themed" hotels are a revival or a recreation, with licenses, of models or traditional or exotic motifs using architecture as thematic claim. This stage will have an important influence on the morphological configuration of the hotels in the Canary Islands. The Decree 4/2001, will take as reference these initial plans and will dissect their forms and proportions to establish them as a rule of mandatory compliance. As Simancas (2010) points out, the application of the tourism regulations established in Decree 10/2001 will have a virtually exclusive effect on hotel accommodation, coinciding with the so-called "tourist moratorium", that began with the Decree 4/2001, which agreed to the formulation of the guidelines of General Management and Tourism. The territorial implementation of the Decree 10/2001 generates a positive relationship between category, accommodations and physical dimensions of the establishment, giving rise to the construction of large hotels, similar to the "Caribbean resort". These are what we have termed as "horizontal hotels", have an irregular volume, occupy an block of buidings, a small height (no more than five floors), as well as a greater physical surface built - to increase the size of the accomodations units and the common spaces - and a high proportion (around 33\%) 
of the part of the unbuilt plot that is destined to green areas, swimming pools, solarium and sports and leisure facilities of common use of the clients. This implies a change in the morphology of the tourist accommodation plant, as well as in the distribution of the uses in which each plot is destined. Good examples of these models that are compatible with the horizontal layout are the hotels "Sheraton La Caleta Resort SPA" (2004) or the hotel "La Plantación del Sur (2005).

\section{Conclusion}

In this partial result of the research, we have shown the morphological evolution of the hotels of mass tourism in the Canary Islands in the past 50 years. The changes in the facilities have been different types being able to concretize them as a conclusion in four (Fig.1 and 2):

-Disposition. By the way of organizing the building on the plot, we have been able to distinguish, in the first decades, terraced, with few services and small plots; hotels in prismatic disposition, representatives of modern architecture in which the base was extended to give rise to collective services; $\mathrm{L}$, U or semi U-shaped hotels in which the building tries to define its own landscape taking advantage of the largest extension of the plot and the provision of central free space for green areas, solariums and swimming pools; landscape hotel in which the height of the volumes is reduced to be distributed in several bodies staggered on larger plots

-Height. The first implementations in the decade of the 60 and 70 will be characterized by the use of modern architecture in which the height and slenderness of the volumes are displays of modernity and quality of its facilities. For several decades the tallest buildings in Tenerife were concentrated in the north of the island. This height in recent patterns has been considerably reduced generating staggered models, in which the impact of the architecture is more integrated in the coastal landscape of the Canary Islands.

- Occupation on the ground. The occupation of the ground floor for uses of complementary services to the hotels has had a pattern of remarkable growth. In the north of the island, the first models utilized the services of the city itself as a necessary complement, gradually to have larger plots with private services specific to each recent. In spite of this progressive rotation toward more closed system or "gate hotels", the urban life of Puerto de la Cruz is maintained with a certain dynamism taking advantage of the walks and pedestrian streets of the destination. However, in the south, the absence from the beginning of this "custom", was the design of a much more closed model. In the last years it has been intended to make compatible with an offering of quality public space and commerce not tied to the hotels.

-Style. Will be in Puerto de la Cruz, pioneer of the tourism on the Canary Islands, where we will find in the decade of the 60 and 70 the first hotels that are consistent with the architecture moment. The international style characterized by laminar blocks in height, free low floors or the use of sockets that contrasted the verticality, were the identity of this time. Later the hotel has been ignoring the more contemporary language of architecture and taking more or less exotic revival and pseudo romantic tributes or interpretations of the vernacular architecture of dubious taste. While in the first decades we could consider hotel architecture situated in the vanguard of the architecture in capital letters, today we cannot say the same.

\section{Notes}

1 The concept of micro-destination is defined as a small geographical unit that is highly dependent on tourism. It is composed of a wide range of tourist facilities and has an image and a typology of tourist (tourist products) differentiated. In addition, a microdestination is a single unit very useful for decision-making in tourism management and planning. For a more operational definition, a micro-destination is a spatial unit of statistical analysis characterized by a high density of establishments of industries characteristic of tourism, homogeneous tourist statistical information, and spatial continuity.

2 Adeje Tourist is formed by: Callao Salvaje, Playa Paraiso, Playa El Duque, Costa Adeje, Torviscas - Fañabe Alto; and Las Americas 
- Los Cristianos: Las Americas - Adeje, Las Americas - Arona, Los Cristianos

Puerto de la Cruz is formed by: Playa Jardin - Maritim; Old Center; Taoro - La Paz; Martianez

\section{References}

Foot, R. (2002) “The shameful architecture', in Mesalles, F., \& Tous, J. (ed.). La arquitectura del Sol-Sunland architecture. Catalunya: Association of Architects of Catalonia et. al, 24-29.

Foot, R. (2015) "Researching on tourism architecture. Four notes to avoid getting lost". QRU: Quaderns de Recerca en Urbanisme, (5/6), 16-43.

Mesalles, F., \& Tous, J. (2002) The Architecture of the sun: Sunland architecture (COAC, College of Architects of Catalonia $=$ Collegi d'Arquitectes de Catalunya, Barcelona)

Beard, R.; Foot, R. (eds.) (1996) Architecture and tourism: Plans and projects (Editorial UPC, CRPP, Department of Town Planning and Housing, Barcelona)

Solà Morales, M. (1993) The forms of urban growth (Editorial UPC, Barcelona)

Simancas Cruz, M. (2015): The Canary Islands tourist moratorium (Publications Service of the University of La Laguna, San Cristóbal de La Laguna)

Hernández, R., \& Santana, A. (2010). Mature tourist destinations in the face of change. Reflections from the Canary Islands (Publications Service of the University of La Laguna, San Cristóbal de La Laguna) 